ISSN 2079-9721

www.mdpi.com/journal/diseases/

Review

\title{
Molecular Mechanism of Gastric Carcinogenesis in Helicobacter pylori-Infected Rodent Models
}

\section{Takeshi Toyoda $^{1}$, Masami Yamamoto ${ }^{2}$, Shinji Takasu ${ }^{1}$, Kumiko Ogawa ${ }^{1}$, Masae Tatematsu ${ }^{3}$ and Tetsuya Tsukamoto ${ }^{4, *}$}

1 Division of Pathology, National Institute of Health Sciences, 1-18-1 Kamiyoga, Setagaya-ku, Tokyo 158-8501, Japan; E-Mails: t-toyoda@nihs.go.jp (T.T.); s-takasu@nihs.go.jp (S.T.); ogawa93@nihs.go.jp (K.O.)

2 Veterinary Nursing and Technology, Nippon Veterinary and Life Science University, 1-7-1 Sakaiminamimachi, Musashino, Tokyo 180-8602, Japan; E-Mail: masami@nvlu.ac.jp

3 Japan Bioassay Research Center, 2445 Hirasawa, Hadano, Kanagawa 257-0015, Japan; E-Mail: keimatate@arion.ocn.ne.jp

4 Department of Diagnostic Pathology I, Fujita Health University School of Medicine, 1-98 Dengakugakubo, Kutsukake-cho, Toyoake, Aichi 470-1192, Japan

* Author to whom correspondence should be addressed; E-Mail: ttsukamt@fujita-hu.ac.jp; Tel.: +81-562-93-2319; Fax: +81-562-95-3761.

Received: 29 April 2014; in revised form: 3 June 2014 / Accepted: 4 June 2014 /

Published: 12 June 2014

Abstract: Since the discovery of Helicobacter pylori (H. pylori), many efforts have been made to establish animal models for the investigation of the pathological features and molecular mechanisms of gastric carcinogenesis. Among the animal models, Mongolian gerbils and mice are particularly useful for the analysis of $H$. pylori-associated inflammatory reactions and gastric cancer development. Inhibitors of oxidative stress, cyclooxygenase-2 (COX-2) and nuclear factor- $\kappa \mathrm{B}$, exert preventive effects on chronic gastritis and the development of adenocarcinomas in $H$. pylori-infected gerbils. Genetically-modified mouse models, including transgenic and knockout mice, have also revealed the importance of $\mathrm{p} 53, \mathrm{COX}-2 /$ prostaglandin, Wnt/ $\beta$-catenin, proinflammatory cytokines, gastrin and type III mucin in the molecular mechanisms of gastric carcinogenesis. Microarray technology is available for comprehensive gene analysis in the gastric mucosa of mouse models, and epigenetics, such as DNA methylation, could be an alternative approach to correlate the observations in animal models with the etiology in humans. 
Keywords: gastric cancer; Helicobacter pylori; molecular mechanism; carcinogenesis; mouse; Mongolian gerbil

\section{Introduction}

Gastric cancer is the fourth most common cancer and second leading cause of cancer-related death in the world [1]. Since Helicobacter pylori (H. pylori) was discovered about 30 years ago [2,3], a lot of epidemiological and experimental studies have revealed a significant relationship between $H$. pylori infection and chronic/atrophic gastritis, peptic ulcer, intestinal metaplasia, gastric lymphoma or cancer development [4-14]. In 2001, Uemura et al. confirmed that stomach cancers develop only in $H$. pylori-infected patients, but none of the uninfected group [15]. Based on the epidemiological findings, $H$. pylori was defined as a "definite carcinogen" by the World Health Organization/International Agency for Research on Cancer (WHO/IARC) in 1994 [16]. Since then, many experimental studies have been performed to investigate the mechanisms of gastric carcinogenesis using animal models, as well as clinical samples. Among animal models, Mongolian gerbils and mice are particularly useful for the analysis of $H$. pylori-associated gastric disorders $[17,18]$. In this article, we will review the research to date for the analysis of the molecular mechanisms of $H$. pylori-associated gastric carcinogenesis using rodent models.

\section{Establishments of Rodent Carcinogenesis Models}

\subsection{Establishment of Chemical Carcinogenesis Model}

Several rodent models have been established to investigate the pathological features and molecular mechanisms of stomach carcinogenesis. These include rats, mice and Mongolian gerbils, and chemical carcinogens were used to induce gastric cancer. Some chemicals used in the early studies, such as benzo[a]pyrene [19], 3-methylcholanthrene [20] and 2-acethylaminofluorene [21], showed a low incidence of gastric lesions in rats. However, it has been reported that oral administration of 4-nitroquinoline 1-oxide (4-NQO) and 4-hydroxyaminoquinoline 1-oxide (4-HAQO) could induce adenocarcinomas of glandular stomach, as well as various other tissues in rats and mice [22,23]. In addition, Sugimura and Fujimura established a rat model using $N$-methyl- $N$ '-nitro- $N$-nitrosoguanidine (MNNG) in drinking water to induce gastric adenocarcinomas with relatively high incidence [24]. Similarly, $N$-methyl- $N$-nitrosourea (MNU) was shown to induce adenocarcinomas in the glandular stomach of mice, including BALB/c [25], $\mathrm{C} 3 \mathrm{H}$ [26] and other strains [27]. In the MNU-treated mice, both differentiated and undifferentiated adenocarcinomas typically develop, showing more significant cellular atypia compared with the MNNG-treated rats. In 1998, Tatematsu et al. have demonstrated that stomach cancers, including well- and poorly-differentiated adenocarcinoma and signet-ring cell carcinoma, also develop in Mongolian gerbils (Meriones unguiculatus), both by MNU or MNNG treatment [28]. The establishment of mouse models has provided new approaches to clarify the molecular mechanisms of gastric carcinogenesis by using genetically-modified animals. 


\subsection{Establishment of H. pylori Infection Models}

Since the discovery of $H$. pylori, various types of experimental animals have been attempted to develop $H$. pylori infection models, but none of the early models could sufficiently reproduce the human situation [29,30]. In 1990, Helicobacter felis (H. felis), a novel H. pylori-related bacterium isolated from cat stomach, was found to be able to colonize the glandular stomach and induce acute and chronic gastritis in germ-free mice [31]. After that, $H$. pylori isolated from human clinical samples were also shown to cause chronic active gastritis in mouse models [32-34]. The Sydney strain of H. pylori (SS1) was established by screening of clinical isolates and showed high colonizing ability in C57BL/6 and BALB/c mice [35]. In addition, a Mongolian gerbil model was successfully established and shown to induce $H$. pylori-associated gastric disorders, including chronic active gastritis, peptic ulcers and intestinal metaplasia, which are closely similar to human [36].

H. pylori infection increases the incidence of MNU- and MNNG-induced adenocarcinomas in gerbils [37-39]. Although early reports suggested that H. pylori infection alone can induce gastric adenocarcinomas in gerbils [40-42], subsequent studies have demonstrated by detailed histopathological assessment that gastric carcinomas are rarely observed in animals treated only with $H$. pylori infection [28,37-39,43], suggesting that $H$. pylori is a strong promoter of gastric carcinogenesis, rather than an initiator. The $H$. pylori-infected and carcinogen-treated gerbil model has been widely used for the investigation of the underlying mechanisms of gastric cancer development $[17,18]$.

While a number of new insights have been provided from the Helicobacter-infected rodent models, there are limitations that should be considered. Most rodent models take months to a year to develop the gastric lesion expected, and almost all gastric cancers in these models are not metastatic. Cytotoxin-associated gene A (CagA), one of the bacterial virulence factors located in cag pathogenicity islands (cagPAI) of the bacterial genome, is known to be associated with the risk of human stomach cancers [44]. H. felis lacks cagPAI and VacA, a vacuolating toxin [45]. Although both two major strains of $H$. pylori, ATCC43504 (also known as NCTC11637) and SS1, possess CagA, the SS1 may not express functional CagA protein [46,47]. Other considerations include the dependency on the gender, diet and genetic background of mice [48]. Taken together, it is considered that CagA-containing strains of $H$. pylori play an especially important role in the investigation of gastric carcinogenesis.

\section{Mechanisms of Gastric Carcinogenesis in Vivo}

Three general factors are considered to impact $H$. pylori-related gastric carcinogenesis: bacterial virulence factors, including CagA, the genetic susceptibility of the host and the environment [49]. As the environmental factor, diet has particularly attracted attention as a major determinant, and epidemiological and experimental studies have demonstrated that consumption of certain natural products can lower gastrointestinal cancer risk in humans and animal models through activation of antioxidative activity and inhibition of inflammatory pathways, such as $\mathrm{COX}-2, \mathrm{NF}-\mathrm{kB}$ and other proinflammatory cytokines. Among the host genetic factors, gene polymorphisms of proinflammatory cytokines are shown to be associated with the susceptibility to gastric carcinogenesis. Gene manipulation technology enabled us to examine the roles of the specific gene in the mechanisms of H. pylori-induced chronic gastritis and cancer development. 


\subsection{Use of Inhibitors}

\subsubsection{Antioxidants}

It has been suggested that inflammation-associated oxidative stress exerts significant effects on gastric carcinogenesis through upregulation of DNA damage [50]. Inhibition of $H$. pylori-induced gastritis and oxidative stress is considered as one of the promising approaches to prevent gastric cancer, because the major determinant factor of stomach carcinogenesis is the degree of $H$. pylori-induced inflammation [51]. To address this hypothesis, Cao et al. examined the inhibitory effect of 4-vinyl-2,6-dimethoxyphenol (canolol), an antioxidant obtained from crude canola oil, on chronic gastritis and gastric cancer development in $H$. pylori-infected gerbils [52]. As a result, H. pylori-induced gastritis, the expression of cyclooxygenase-2 (COX-2) and inducible nitric oxide synthase (iNOS) and serum 8-hydroxy-2'-deoxyguanosine (8-OHdG) levels were significantly decreased in canolol-treated gerbils compared with the non-treated groups. In addition, the incidence of gastric adenocarcinomas was also reduced by canolol treatment, indicating that oxygen radical scavengers could prevent $H$. pylori-associated gastritis and carcinogenesis in gerbils. Interestingly, the canolol treatment did not affect the viable $H$. pylori count, suggesting that the degree of H. pylori-induced inflammation is a more important determining factor than the existence of the bacteria. Other naturally-derived compounds, such as sulforaphane from broccoli sprouts $[53,54]$, and nordihydroguaiaretic acid found in the creosote bush [55], a common shrub of North America, have been also shown to be effective for the prevention of $H$. pylori-induced gastric disorders in rodent models through the antioxidative activity.

\subsubsection{COX-2 Inhibitors}

COX-2 has been shown to be involved in the processes of inflammation and carcinogenesis [56], and previous studies indicate that COX-2 expression is associated with $H$. pylori-induced gastritis and stomach carcinogenesis in humans [57,58]. H. pylori infection and excessive salt intake synergistically enhance COX-2 and iNOS expression in the gastric mucosa of gerbils [59]. Thus, the inhibition of COX-2 may be a promising target for reducing the risk of gastric cancer. Actually, COX-2 selective inhibitors, such as etodolac and celecoxib, have been shown to exert preventive effects on the stomach cancer of $H$. pylori-infected gerbils [60,61].

Recent epidemiological studies have demonstrated that eradication of $H$. pylori has preventive effects on gastric cancer development [62,63]. However, since not all tumors are prevented by H. pylori eradication [64], the search for new approaches and alternative therapies for the prevention of stomach carcinogenesis after eradication continues to be very important. Because inflammatory reactions against the bacterium disappear after eradication, it is necessary to target factors directly regulating the proliferation and progression of tumor or precancerous cells for the prevention of gastric carcinogenesis after eradication. It has been demonstrated that COX-2 inhibitors could regress the early stage tumors in the intestine of mice and rats $[65,66]$. Therefore, there is another possibility that COX-2 inhibitors could be applicable to the regression of the remaining precancerous lesion and prevention of gastric cancer occurrence after $H$. pylori eradication. 


\subsubsection{NF- $\mathrm{KB}$ inhibitors}

Nuclear factor- $\kappa \mathrm{B}(\mathrm{NF}-\mathrm{\kappa B})$ plays a central role in host inflammatory responses and carcinogenesis [67]. $H$. pylori infection activates the NF- $\kappa \mathrm{B}$ signaling pathway, and NF- $\mathrm{BB}$-mediated cytokine expression is essentially involved with $H$. pylori-induced gastritis in gerbils and mice [68-71]. Ogura et al. reported that the degree of gastritis induced by a mutant strain of $H$. pylori lacking capacity for NF- $\mathrm{BB}$ activation is lower than that with wild-type infection in gerbils [72]. Therefore, it is considered that inhibition of NF- $\kappa \mathrm{B}$ could be a target for the prevention of $H$. pylori-associated gastric cancer [73]. Caffeic acid phenethyl ester (CAPE), a naturally-derived NF- $\kappa \mathrm{B}$ inhibitor, was analyzed on $H$. pylori-induced chronic gastritis using the gerbil model [74]. CAPE treatment significantly attenuated infiltration of neutrophils and mononuclear cells and the expression of the NF- $\mathrm{B}$ p50 subunit and phospho-IкB- $\alpha$ in the antrum of $H$. pylori-infected gerbils. The proliferative activity of epithelial cells, both in the antrum and corpus, were markedly reduced by CAPE treatment. In addition, mRNA expression of inflammatory factors, such as tumor necrosis factor- $\alpha$ (Tnf- $\alpha)$, interferon- $\gamma$, interleukin (Il)-2, Il-6, KC (Il-8 homologue) and $i N o s$, was significantly decreased in the pyloric mucosa. These results indicate that CAPE has inhibitory effects on $H$. pylori-induced gastritis in gerbils through the suppression of NF- $\mathrm{KB}$ activation and may have the potential for the prevention and therapy of $H$. pylori-associated gastric disorders [74].

\subsubsection{Statins}

Statins, potent inhibitors of 3-hydroxy-3-methylglutaryl coenzyme A (HMG-CoA) reductase, are widely used drugs for the treatment of hypercholesterolemia, with beneficial effects on cardiovascular disease $[75,76]$. Several studies have suggested that statins have chemopreventive effects on various types of cancers [77-79]. To clarify the effects of statins on gastric carcinogenesis, pitavastatin was examined in $H$. pylori-infected gerbil and mouse models [80]. The incidences of $H$. pylori-associated gastric adenocarcinomas and the degrees of chronic gastritis were not decreased by pitavastatin with upregulation of $I 1-1 \beta$ and $T n f-\alpha$ mRNA expression in the pyloric mucosa. Interestingly, serum total cholesterol (T-Chol), triglyceride (TG) and low-density lipoprotein (LDL) levels were significantly increased by pitavastatin treatment in the $H$. pylori-infected groups. In the short-term study, H. pylori-infected gerbils and mice also showed upregulation of TG levels by pitavastatin, whereas T-Chol was markedly reduced, and LDL exhibited a tendency for decrease in non-infected animals. These findings indicate that pitavastatin has no suppressive effects on chronic gastritis and stomach carcinogenesis in H. pylori-infected rodent models, and the H. pylori infection and following severe chronic gastritis interfere with the cholesterol-lowering effects of pitavastatin [80].

\subsection{Use of Genetically-Modified Animals}

Genetically-modified rodent models have been used for the investigation of the mechanisms of gastric carcinogenesis. The target genes include the oncogenes and tumor-suppressor genes directly associated with the transformation of gastric epithelial cells, the signaling pathways and cytokines involved in the proinflammatory responses induced by Helicobacter infection; and the environmental regulatory factors for colonization and proliferation of $H$. pylori in the glandular stomach. 


\subsection{1. p53 Tumor Suppressor Gene}

The p53 tumor suppressor gene is known to be frequently mutated in various types of human cancer [81]. However, MNNG-induced rat stomach adenocarcinomas had a mutation of the p53 gene in only one of 10 cases [82]. In addition, no mutations in exons 5-8 were found in a total of 30 gastric tumors in MNU-treated mice [83]. In 1992, the p53 knockout mouse has been established by Donehower et al. as a powerful tool for functional analysis of carcinogenesis [84-86]. Yamamoto et al. have investigated the susceptibility of p53 nullizygote $(-/-)$, heterozygote $(+/-)$ and wild-type $(+/+)$ mice to MNU-induced pepsinogen altered pyloric glands (PAPGs) and stomach carcinogenesis [87]. PAPGs are putative precancerous lesions immunohistochemically stained weakly or negative for pepsinogen 1 (Pg 1) in mice and rats [88-90]. At five weeks, there were more PAPGs both in slightly irregular glands and the normal-looking mucosa of MNU-treated p53 (-/-) mice than the control mice with consistent expression of Pg 1 in the pyloric gland. The frequency of PAPGs in MNU-treated p53 $(-/-)$ mice was significantly elevated compared with the values for MNU-treated p53 (+/+) and (+/-) mice and the control groups. At 15 weeks, adenomas were observed in two of $21 \mathrm{p} 53(+/-)$ and six of 10 p53 (-/-) mice, and adenocarcinoma was detected in one of 10 p53 (-/-) animals. There was a significant tendency toward malignancy in the tumors developed in p53 (-/-) mice compared with $(+/-)$ and wild-type mice. At 40 weeks, no significant difference in the incidences of gastric adenoma and adenocarcinoma between p53 $(+/+)$ and $(+/-)$ mice was observed [87,91]. PCR-single strand conformation polymorphism (SSCP) analysis revealed that none of the 68 gastric tumors derived from the 15- and 40-week experiments has any mutations in the p53 gene, although the simultaneous development of lymphoma and sarcoma in MNU-treated groups showed mutations in the wild-type allele of p53 [87]. These results indicate that p53 (-/-) mice are more susceptible to MNU-induced gastric carcinogenesis than p53 (+/-) and wild-type mice. Thus, it is suggested that p53 may act as a gatekeeper in the gastric carcinogenesis of rodents, rather than as a direct target of chemical carcinogen.

\subsubsection{COX-2/Prostaglandin}

COX-2 is a rate-limiting enzyme for prostanoid biosynthesis, and prostaglandin E2 (PGE2) is known to be most important for cancer development. In 2004, Oshima et al. established K19-C2mE mice simultaneously expressing COX-2 and microsomal prostaglandin E synthase (mPGES)-1 under a keratin 19 (K19) promoter in the gastric epithelial cells, and the transgenic mice developed proliferative lesions in the glandular stomach with significant infiltration of macrophages [92]. They revealed the importance of the COX-2/mPGES-1 pathway in Helicobacter-associated gastric carcinogenesis, since H. felis infection also upregulated epithelial expression of COX-2 and PGE2. TNF- $\alpha$-dependent inflammation is required for the development of proliferative lesions in the COX-2/mPGES-1 mice [93]. COX-2 and mPGES-1 expression progressed metaplastic lesions observed in K19-Wnt1 transgenic mice to dysplastic gastric tumors [94]. In addition, additional expression of noggin, a bone morphogenetic protein (BMP) antagonist, in K19-C2mE mice caused gastric hamartoma that resembles human juvenile polyposis syndrome [95]. CD44-positive stem-like cells are candidates for the origin of gastric tumor in K19-Wnt1/C2mE mice and triggered by PGE2-induced inflammation and Wnt signaling [96]. The germ-free colony of K19-Wnt1/C2mE mice 
develops less gastric tumors, and additional $H$. felis infection recovers the tumorigenesis, suggesting that bacterial infection and inflammation play a critical role in gastric carcinogenesis [97]. Takasu et al. has demonstrated that $H$. pylori (SS1) infection and $\mathrm{MNU}$ treatment could induce gastric adenocarcinomas, not only in the antrum, but also in the corpus of $\mathrm{K} 19-\mathrm{C} 2 \mathrm{mE}$ mice, providing a better model for increasing proximal gastric cancers [98].

\subsubsection{Wnt/ $\beta$-Catenin}

The activation of Wnt/ $\beta$-catenin signaling mainly caused by mutations in exon 3 of the $\beta$-catenin gene is found in 30\%-50\% of gastric cancers, suggesting an important role of Wnt signaling in stomach carcinogenesis [99]. In MNNG-induced rat adenocarcinomas, four of twenty-two tumors showed nuclear localization of $\beta$-catenin with the characteristic mutation of exon 3 [100]. This study suggested that $\beta$-catenin mutations could be associated with the progression of chemical-induced rat adenocarcinoma at the late stage. In the gerbil model, only one of forty-five adenocarcinomas induced by $H$. pylori infection and MNU treatment showed nuclear accumulation of $\beta$-catenin with gene mutation [101]. Nuclear localization of $\beta$-catenin in stomach cancers is more frequently observed in mouse models. It has been reported that $H$. pylori infection enhances the activation of $\beta$-catenin in the gastric carcinogenesis of the pyloric region, especially in K19-C2mE transgenic mice [98]. Du et al. suggested that Sox 17 expression prevents malignant progression of gastric tumors in K19-Wnt1/C2mE mice through the regulation of Wnt activity [102].

\subsubsection{Proinflammatory Cytokines}

H. pylori infection-mediated cytokine expression is essentially involved in the development of chronic gastritis and stomach tumors. TNF- $\alpha$ and IL-1 $\beta$ are considered to be particularly important, because epidemiological studies have suggested that their polymorphisms are associated with the increased risk of gastric carcinogenesis [103-105]. Oshima et al. recently reported that additional knockout of TNF- $\alpha$ or TNF- $\alpha$ receptor results in the significant suppression of gastric tumor development in the $\mathrm{K} 19-\mathrm{Wnt} 1 / \mathrm{C} 2 \mathrm{mE}$ mice [106]. H. pylori-associated gastric carcinogenesis was also attenuated in IL-1 $\beta$ knockout mice with decreased infiltration of neutrophils and macrophages [107]. MyD88 is one of the adaptor molecules in host inflammatory responses, and a recent study demonstrated that MyD88-deficient mice show the early onset of Helicobacter-induced gastric dysplasia with increased expression of TNF- $\alpha$, IL-1 $\beta$, INF- $\gamma$ and IL-6 [108]. Thus, these studies indicate that proinflammatory cytokines and related pathways could be effective targets of preventive and therapeutic strategies for stomach cancer.

\subsubsection{Gastrin}

The association between hypergastrinemia and gastric carcinogenesis remains unclear. Most patients infected with $H$. pylori exhibit relatively low serum gastrin levels along with the progression of atrophic gastritis. Actually, it has been reported that gastrin-deficient mice show increased gastric inflammation and tumor development mainly in the antrum [109,110]. On the other hand, Wang and their colleagues have demonstrated that chronic hypergastrinemia in the insulin-gastrin (INS-GAS) 
transgenic mice could induce gastric cancer in the corpus, and $H$. felis and $H$. pylori infection synergistically enhances the progression of tumors [111,112], suggesting that gastrin exerts distinct functions in the antrum and corpus. The INS-GAS mice have been widely used for various fields of investigation of gastric carcinogenesis [113].

\subsubsection{Type III Mucin}

The gastric mucosa are covered with two types of mucin, surface and gland mucins. Gland mucin is secreted from mucous neck cells and pyloric gland cells and contains $O$-linked oligosaccharides ( $O$-glycans) with terminal $\alpha$,4-linked $N$-acetylglucosamine residues ( $\alpha$ GlcNAc) [114]. It has been revealed that $H$. pylori could colonize and proliferate not in the gland mucous layer, but in the surface mucous layer, because the $O$-glycans have antimicrobial effects on $H$. pylori $[115,116]$. Karasawa et al. established A4gnt(-/-) mice, completely lacking aGlcNAc expression in the gastric gland mucin, and showed the spontaneous development of gastric adenocarcinomas without $H$. pylori infection [117]. The expression of pro-inflammatory cytokines and growth factors is increased in the gastric mucosa of A4gnt(-/-) mice, suggesting that the absence of $\alpha$ GlcNAc triggered inflammatory responses followed by gastric tumorigenesis. In human cases, the loss of $\alpha$ GlcNAc in well-differentiated adenocarcinoma with MUC6 expression is shown to be significantly associated with tumor malignancy and poor prognosis [118].

\subsection{Microarray and Epigenetics}

\subsubsection{Microarray}

Microarray technology has been applied to investigate global gene expression patterns in both human samples and animal models of gastric disorder [119-123]. While there are many reports investigating the gene expression profiles of $H$. pylori-treated gastric cell lines, cell culture studies do not always reflect the in vivo microenvironment, including host immune responses and stromal-epithelial interactions in cancers. Since there is little information available for the gerbil genome, attention has focused on mouse models. Itadani et al. demonstrated that gastric tumors in K19-Wnt1/C2mE transgenic mice are closely similar to intestinal-type stomach cancer regarding the gene expression profiles [124]. Among thirty-five candidate genes upregulated in $H$. pylori-infected and high-salt diet-treated mice, $C d 177$ expression is found to be a novel prognostic factor of patients with advanced gastric adenocarcinoma [125]. Thus, it is considered that the mouse model is suitable for the investigation of the gene expression profile associated with stomach carcinogenesis.

\subsubsection{Epigenetics}

DNA methylation is one of the epigenetic mechanisms for gene regulation and deeply associated with cancer development of various tissues. Aberrant DNA methylation is induced by aging and chronic inflammation, including ulcerative colitis, chronic hepatitis and H. pylori-induced gastritis [126]. Niwa et al. revealed that $H$. pylori-associated inflammation, rather than infection itself, is responsible for inducing the aberrant DNA methylation in gastric epithelial cells using the gerbil model [127]. The authors also demonstrated that specific types of inflammation caused by Helicobacter infection, not 
the increased cell proliferation, has a strong potential to induce aberrant DNA methylation in the gastric mucosa [46]. A DNA demethylating agent, 5-aza-2'-deoxycytidine (5-aza-dC), could prevent gastric carcinogenesis in $H$. pylori-infected gerbils, suggesting that the suppression of aberrant DNA methylation is a target for the prevention of stomach cancers [128]. In addition, novel risk markers of gastric cancer were identified by the microarray analysis for hypermethylated $\mathrm{CpG}$ islands [129]. A recent study revealed that CagA of $H$. pylori causes aberrant epigenetic silencing of let-7 followed by upregulation of Ras oncoprotein using in vitro experiments and an in vivo mouse model [130].

\section{Conclusions}

H. pylori infection is one of the most important risk factors for gastric carcinogenesis in human stomach. Since the discovery of H. pylori, the Mongolian gerbil and mouse have become useful model animals for the investigation of stomach carcinogenesis, the search for chemopreventive agents and molecular mechanisms. As already revealed by the gerbil model, H. pylori itself is a potent promoter in stomach carcinogenesis through chronic gastritis. The genetically-modified mouse models play a significant role to clarify what kind of molecules or genes act as a bridge between the H. pylori-induced inflammatory process and gastric cancer development. The global gene expression analysis and epigenetic approaches will become much more important for solving the complicated interaction.

\section{Acknowledgments}

This study was supported by Grant-in-Aid for the Third-term Comprehensive 10-year Strategy for Cancer Control and the Health Labour Sciences Research Grant from the Ministry of Health, Labour and Welfare, Japan, and Grant-in-Aid for Young Scientists (B) (22700935) and Scientific Research (C) (26430132) from the Japan Society for the Promotion of Science (JSPS), Japan.

\section{Author Contributions}

T. Toyoda, M. Yamamoto, S. Takasu, K. Ogawa, M. Tatematsu and T. Tsukamoto all participated in designing, writing and editing of the review.

\section{Conflicts of Interest}

The authors declare no conflict of interest.

\section{References}

1. Jemal, A.; Bray, F.; Center, M.M.; Ferlay, J.; Ward, E.; Forman, D. Global cancer statistics. CA Cancer J. Clin. 2011, 61, 69-90.

2. Marshall, B.J.; Warren, J.R. Unidentified curved bacilli in the stomach of patients with gastritis and peptic ulceration. Lancet 1984, 1, 1311-1315.

3. Warren, J.R.; Marshall, B. Unidentified curved bacilli on gastric epithelium in active chronic gastritis. Lancet 1983, 321, 1273-1275. 
4. Hu, P.J.; Li, Y.Y.; Zhou, M.H.; Chen, M.H.; Du, G.G.; Huang, B.J.; Mitchell, H.M.; Hazell, S.L. Helicobacter pylori associated with a high prevalence of duodenal ulcer disease and a low prevalence of gastric cancer in a developing nation. Gut 1995, 36, 198-202.

5. Craanen, M.E.; Dekker, W.; Blok, P.; Ferwerda, J.; Tytgat, G.N. Intestinal metaplasia and Helicobacter pylori: An endoscopic bioptic study of the gastric antrum. Gut 1992, 33, 16-20.

6. Parsonnet, J.; Friedman, G.D.; Vandersteen, D.P.; Chang, Y.; Vogelman, J.H.; Orentreich, N.; Sibley, R.K. Helicobacter pylori infection and the risk of gastric carcinoma. N. Engl. J. Med. 1991, 325, 1127-1131.

7. Nomura, A.; Stemmermann, G.N.; Chyou, P.H.; Kato, I.; Perez-Perez, G.I.; Blaser, M.J. Helicobacter pylori infection and gastric carcinoma among Japanese Americans in Hawaii. N. Engl. J. Med. 1991, 325, 1132-1136.

8. Forman, D.; Newell, D.G.; Fullerton, F.; Yarnell, J.W.; Stacey, A.R.; Wald, N.; Sitas, F. Association between infection with Helicobacter pylori and risk of gastric cancer: Evidence from a prospective investigation. Br. Med. J. 1991, 302, 1302-1305.

9. Graham, D.Y.; Lew, G.M.; Klein, P.D.; Evans, D.G.; Evans, D.J., Jr.; Saeed, Z.A.; Malaty, H.M. Effect of treatment of Helicobacter pylori infection on the long-term recurrence of gastric or duodenal ulcer. A randomized, controlled study. Ann. Intern. Med. 1992, 116, 705-708.

10. Kuipers, E.J.; Uyterlinde, A.M.; Pena, A.S.; Roosendaal, R.; Pals, G.; Nelis, G.F.; Festen, H.P.; Meuwissen, S.G. Long-term sequelae of Helicobacter pylori gastritis. Lancet 1995, 345, 1525-1528.

11. Asaka, M.; Kato, M.; Kudo, M.; Katagiri, M.; Nishikawa, K.; Koshiyama, H.; Takeda, H.; Yoshida, J.; Graham, D.Y. Atrophic changes of gastric mucosa are caused by Helicobacter pylori infection rather than aging: Studies in asymptomatic Japanese adults. Helicobacter 1996, 1, 52-56.

12. Huang, J.Q.; Sridhar, S.; Chen, Y.; Hunt, R.H. Meta-analysis of the relationship between Helicobacter pylori seropositivity and gastric cancer. Gastroenterology 1998, 114, 1169-1179.

13. Parsonnet, J.; Hansen, S.; Rodriguez, L.; Gelb, A.B.; Warnke, R.A.; Jellum, E.; Orentreich, N.; Vogelman, J.H.; Friedman, G.D. Helicobacter pylori infection and gastric lymphoma. N. Engl. J. Med. 1994, 330, 1267-1271.

14. The EUROGAST Study Group. An international association between Helicobacter pylori infection and gastric cancer. Lancet 1993, 341, 1359-1362.

15. Uemura, N.; Okamoto, S.; Yamamoto, S.; Matsumura, N.; Yamaguchi, S.; Yamakido, M.; Taniyama, K.; Sasaki, N.; Schlemper, R.J. Helicobacter pylori infection and the development of gastric cancer. N. Engl. J. Med. 2001, 345, 784-789.

16. IARC Working Group on the Evaluation of Carcinogenic Risks to Humans, Infection with Helicobacter pylori. In Schistosomes, Liver Flukes and Helibacter pylori; World Health Organization / International Agency for Research on Cancer: Lyon, France, 1994; Volume 61, pp. 177-241.

17. Tsukamoto, T.; Mizoshita, T.; Tatematsu, M. Animal models of stomach carcinogenesis. Toxicol. Pathol. 2007, 35, 636-648.

18. Tsukamoto, T.; Toyoda, T.; Mizoshita, T.; Tatematsu, M. Helicobacter pylori infection and gastric carcinogenesis in rodent models. Semin. Immunopathol. 2013, 35, 177-190.

19. Rusch, H.P.; Baumann, C.A.; Maison, G.L. Production of internal tumors with chemical carcinogens. Arch. Pathol. 1940, 29, 8-19. 
20. Stewart, H.L.; Snell, K.C. Histopathogenesis of carcinoma induced in the glandular stomach of C57BL mice by the intramural injection of 20-methylcholanthrene. J. Natl. Cancer Inst. 1958, 21, 999-1035.

21. Wilson, R.H.; De Eds, F.; Cox, A.J., Jr. The toxicity and carcinogenic activity of 2-acetaminofluorene. Cancer Res. 1941, 1, 595-608.

22. Mori, K. Carcinoma of the glandular stomach of mice by instillation of 4-nitroquinoline 1-oxide. Gann 1967, 58, 389-393.

23. Mori, K.; Ohta, A. Carcinoma of the glandular stomach of mice induced by 4-hydroxyaminoquinoline 1-oxide. Gann 1967, 58, 551-554.

24. Sugimura, T.; Fujimura, S. Tumour production in glandular stomach of rat by $N$-methyl- $N$ '-nitro$N$-nitrosoguanidine. Nature 1967, 216, 943-944.

25. Tatematsu, M.; Ogawa, K.; Hoshiya, T.; Shichino, Y.; Kato, T.; Imaida, K.; Ito, N. Induction of adenocarcinomas in the glandular stomach of BALB/c mice treated with $N$-methyl- $N$ nitrosourea. Jpn. J. Cancer Res. 1992, 83, 915-918.

26. Tatematsu, M.; Yamamoto, M.; Iwata, H.; Fukami, H.; Yuasa, H.; Tezuka, N.; Masui, T.; Nakanishi, H. Induction of glandular stomach cancers in $\mathrm{C} 3 \mathrm{H}$ mice treated with $\mathrm{N}$-methyl- $N$ nitrosourea in the drinking water. Jpn. J. Cancer Res. 1993, 84, 1258-1264.

27. Yamamoto, M.; Furihata, C.; Ogiu, T.; Tsukamoto, T.; Inada, K.; Hirano, K.; Tatematsu, M. Independent variation in susceptibilities of six different mouse strains to induction of pepsinogen-altered pyloric glands and gastric tumor intestinalization by $N$-methyl- $N$-nitrosourea. Cancer Lett. 2002, 179, 121-132.

28. Tatematsu, M.; Yamamoto, M.; Shimizu, N.; Yoshikawa, A.; Fukami, H.; Kaminishi, M.; Oohara, T.; Sugiyama, A.; Ikeno, T. Induction of glandular stomach cancers in Helicobacter pylori-sensitive Mongolian gerbils treated with $N$-methyl- $N$-nitrosourea and $N$-methyl- $N$ '-nitro$N$-nitrosoguanidine in drinking water. Jpn. J. Cancer Res. 1998, 89, 97-104.

29. Krakowka, S.; Morgan, D.R.; Kraft, W.G.; Leunk, R.D. Establishment of gastric Campylobacter pylori infection in the neonatal gnotobiotic piglet. Infect. Immun. 1987, 55, 2789-2796.

30. Radin, M.J.; Eaton, K.A.; Krakowka, S.; Morgan, D.R.; Lee, A.; Otto, G.; Fox, J. Helicobacter pylori gastric infection in gnotobiotic beagle dogs. Infect. Immun. 1990, 58, 2606-2612.

31. Lee, A.; Fox, J.G.; Otto, G.; Murphy, J. A small animal model of human Helicobacter pylori active chronic gastritis. Gastroenterology 1990, 99, 1315-1323.

32. Karita, M.; Kouchiyama, T.; Okita, K.; Nakazawa, T. New small animal model for human gastric Helicobacter pylori infection: Success in both nude and euthymic mice. Am. J. Gastroenterol. 1991, 86, 1596-1603.

33. Karita, M.; Li, Q.; Cantero, D.; Okita, K. Establishment of a small animal model for human Helicobacter pylori infection using germ-free mouse. Am. J. Gastroenterol. 1994, 89, 208-213.

34. Marchetti, M.; Arico, B.; Burroni, D.; Figura, N.; Rappuoli, R.; Ghiara, P. Development of a mouse model of Helicobacter pylori infection that mimics human disease. Science 1995, 267, $1655-1658$.

35. Lee, A.; O'Rourke, J.; De Ungria, M.C.; Robertson, B.; Daskalopoulos, G.; Dixon, M.F. A standardized mouse model of Helicobacter pylori infection: Introducing the Sydney strain. Gastroenterology 1997, 112, 1386-1397. 
36. Hirayama, F.; Takagi, S.; Yokoyama, Y.; Iwao, E.; Ikeda, Y. Establishment of gastric Helicobacter pylori infection in Mongolian gerbils. J. Gastroenterol. 1996, 31, 24-28.

37. Sugiyama, A.; Maruta, F.; Ikeno, T.; Ishida, K.; Kawasaki, S.; Katsuyama, T.; Shimizu, N.; Tatematsu, M. Helicobacter pylori infection enhances $N$-methyl- $N$-nitrosourea-induced stomach carcinogenesis in the Mongolian gerbil. Cancer Res. 1998, 58, 2067-2069.

38. Shimizu, N.; Inada, K.; Nakanishi, H.; Tsukamoto, T.; Ikehara, Y.; Kaminishi, M.; Kuramoto, S.; Sugiyama, A.; Katsuyama, T.; Tatematsu, M. Helicobacter pylori infection enhances glandular stomach carcinogenesis in Mongolian gerbils treated with chemical carcinogens. Carcinogenesis 1999, 20, 669-676.

39. Shimizu, N.; Inada, K.I.; Tsukamoto, T.; Nakanishi, H.; Ikehara, Y.; Yoshikawa, A.; Kaminishi, M.; Kuramoto, S.; Tatematsu, M. New animal model of glandular stomach carcinogenesis in Mongolian gerbils infected with Helicobacter pylori and treated with a chemical carcinogen. J. Gastroenterol. 1999, 34, 61-66.

40. Hirayama, F.; Takagi, S.; Iwao, E.; Yokoyama, Y.; Haga, K.; Hanada, S. Development of poorly differentiated adenocarcinoma and carcinoid due to long-term Helicobacter pylori colonization in Mongolian gerbils. J. Gastroenterol. 1999, 34, 450-454.

41. Watanabe, T.; Tada, M.; Nagai, H.; Sasaki, S.; Nakao, M. Helicobacter pylori infection induces gastric cancer in Mongolian gerbils. Gastroenterology 1998, 115, 642-648.

42. Honda, S.; Fujioka, T.; Tokieda, M.; Satoh, R.; Nishizono, A.; Nasu, M. Development of Helicobacter pylori-induced gastric carcinoma in Mongolian gerbils. Cancer Res. 1998, 58, 4255-4259.

43. Shimizu, N.; Ikehara, Y.; Inada, K.; Nakanishi, H.; Tsukamoto, T.; Nozaki, K.; Kaminishi, M.; Kuramoto, S.; Sugiyama, A.; Katsuyama, T.; et al. Eradication diminishes enhancing effects of Helicobacter pylori infection on glandular stomach carcinogenesis in Mongolian gerbils. Cancer Res. 2000, 60, 1512-1514.

44. Huang, J.Q.; Zheng, G.F.; Sumanac, K.; Irvine, E.J.; Hunt, R.H. Meta-analysis of the relationship between cagA seropositivity and gastric cancer. Gastroenterology 2003, 125, 1636-1644.

45. Arnold, I.C.; Zigova, Z.; Holden, M.; Lawley, T.D.; Rad, R.; Dougan, G.; Falkow, S.; Bentley, S.D.; Muller, A. Comparative whole genome sequence analysis of the carcinogenic bacterial model pathogen Helicobacter felis. Genome Biol. Evol. 2011, 3, 302-308.

46. Hur, K.; Niwa, T.; Toyoda, T.; Tsukamoto, T.; Tatematsu, M.; Yang, H.K.; Ushijima, T. Insufficient role of cell proliferation in aberrant DNA methylation induction and involvement of specific types of inflammation. Carcinogenesis 2011, 32, 35-41.

47. Crabtree, J.E.; Ferrero, R.L.; Kusters, J.G. The mouse colonizing Helicobacter pylori strain SS1 may lack a functional cag pathogenicity island. Helicobacter 2002, 7, 139-140.

48. van Doorn, N.E.; Namavar, F.; Sparrius, M.; Stoof, J.; van Rees, E.P.; van Doorn, L.J.; Vandenbroucke-Grauls, C.M. Helicobacter pylori-associated gastritis in mice is host and strain specific. Infect. Immun. 1999, 67, 3040-3046.

49. Romano, M.; Ricci, V.; Zarrilli, R. Mechanisms of disease: Helicobacter pylori-related gastric carcinogenesis--implications for chemoprevention. Nat. Clin. Pract. Gastroenterol. Hepatol. 2006, 3, 622-632. 
50. Naito, Y.; Yoshikawa, T. Molecular and cellular mechanisms involved in Helicobacter pyloriinduced inflammation and oxidative stress. Free Radic. Biol. Med. 2002, 33, 323-336.

51. Cao, X.; Tsukamoto, T.; Nozaki, K.; Tanaka, H.; Cao, L.; Toyoda, T.; Takasu, S.; Ban, H.; Kumagai, T.; Tatematsu, M. Severity of gastritis determines glandular stomach carcinogenesis in Helicobacter pylori-infected Mongolian gerbils. Cancer Sci. 2007, 98, 478-483.

52. Cao, X.; Tsukamoto, T.; Seki, T.; Tanaka, H.; Morimura, S.; Cao, L.; Mizoshita, T.; Ban, H.; Toyoda, T.; Maeda, H.; et al. 4-Vinyl-2,6-dimethoxyphenol (canolol) suppresses oxidative stress and gastric carcinogenesis in Helicobacter pylori-infected carcinogen-treated Mongolian gerbils. Int. J. Cancer 2008, 122, 1445-1454.

53. Yanaka, A.; Fahey, J.W.; Fukumoto, A.; Nakayama, M.; Inoue, S.; Zhang, S.; Tauchi, M.; Suzuki, H.; Hyodo, I.; Yamamoto, M. Dietary sulforaphane-rich broccoli sprouts reduce colonization and attenuate gastritis in Helicobacter pylori-infected mice and humans. Cancer Prev. Res. 2009, 2, 353-360.

54. Fahey, J.W.; Haristoy, X.; Dolan, P.M.; Kensler, T.W.; Scholtus, I.; Stephenson, K.K.; Talalay, P.; Lozniewski, A. Sulforaphane inhibits extracellular, intracellular, and antibiotic-resistant strains of Helicobacter pylori and prevents benzo[a]pyrene-induced stomach tumors. Proc. Natl. Acad. Sci. USA 2002, 99, 7610-7615.

55. Toyoda, T.; Tsukamoto, T.; Mizoshita, T.; Nishibe, S.; Deyama, T.; Takenaka, Y.; Hirano, N.; Tanaka, H.; Takasu, S.; Ban, H.; et al. Inhibitory effect of nordihydroguaiaretic acid, a plant lignan, on Helicobacter pylori-associated gastric carcinogenesis in Mongolian gerbils. Cancer Sci. 2007, 98, 1689-1695.

56. Prescott, S.M.; Fitzpatrick, F.A. Cyclooxygenase-2 and carcinogenesis. Biochim. Biophys. Acta 2000, 1470, M69-M78.

57. Fu, S.; Ramanujam, K.S.; Wong, A.; Fantry, G.T.; Drachenberg, C.B.; James, S.P.; Meltzer, S.J.; Wilson, K.T. Increased expression and cellular localization of inducible nitric oxide synthase and cyclooxygenase 2 in Helicobacter pylori gastritis. Gastroenterology 1999, 116, 1319-1329.

58. Thiel, A.; Mrena, J.; Ristimaki, A. Cyclooxygenase-2 and gastric cancer. Cancer Metast. Rev. 2011, 30, 387-395.

59. Toyoda, T.; Tsukamoto, T.; Hirano, N.; Mizoshita, T.; Kato, S.; Takasu, S.; Ban, H.; Tatematsu, M. Synergistic upregulation of inducible nitric oxide synthase and cyclooxygenase-2 in gastric mucosa of Mongolian gerbils by a high-salt diet and Helicobacter pylori infection. Histol. Histopathol. 2008, 23, 593-599.

60. Futagami, S.; Suzuki, K.; Hiratsuka, T.; Shindo, T.; Hamamoto, T.; Tatsuguchi, A.; Ueki, N.; Shinji, Y.; Kusunoki, M.; Wada, K.; et al. Celecoxib inhibits Cdx2 expression and prevents gastric cancer in Helicobacter pylori-infected Mongolian gerbils. Digestion 2006, 74, 187-198.

61. Magari, H.; Shimizu, Y.; Inada, K.; Enomoto, S.; Tomeki, T.; Yanaoka, K.; Tamai, H.; Arii, K.; Nakata, H.; Oka, M.; et al. Inhibitory effect of etodolac, a selective cyclooxygenase-2 inhibitor, on stomach carcinogenesis in Helicobacter pylori-infected Mongolian gerbils. Biochem. Biophys. Res. Commun. 2005, 334, 606-612. 
62. Yanaoka, K.; Oka, M.; Ohata, H.; Yoshimura, N.; Deguchi, H.; Mukoubayashi, C.; Enomoto, S.; Inoue, I.; Iguchi, M.; Maekita, T.; et al. Eradication of Helicobacter pylori prevents cancer development in subjects with mild gastric atrophy identified by serum pepsinogen levels. Int. J. Cancer 2009, 125, 2697-2703.

63. Fuccio, L.; Zagari, R.M.; Eusebi, L.H.; Laterza, L.; Cennamo, V.; Ceroni, L.; Grilli, D.; Bazzoli, F. Meta-analysis: Can Helicobacter pylori eradication treatment reduce the risk for gastric cancer? Ann. Intern. Med. 2009, 151, 121-128.

64. Fukase, K.; Kato, M.; Kikuchi, S.; Inoue, K.; Uemura, N.; Okamoto, S.; Terao, S.; Amagai, K.; Hayashi, S.; Asaka, M. Effect of eradication of Helicobacter pylori on incidence of metachronous gastric carcinoma after endoscopic resection of early gastric cancer: An open-label, randomised controlled trial. Lancet 2008, 372, 392-397.

65. Chiu, C.H.; McEntee, M.F.; Whelan, J. Sulindac causes rapid regression of preexisting tumors in Min/+ mice independent of prostaglandin biosynthesis. Cancer Res. 1997, 57, 4267-4273.

66. Reddy, B.S.; Maruyama, H.; Kelloff, G. Dose-related inhibition of colon carcinogenesis by dietary piroxicam, a nonsteroidal antiinflammatory drug, during different stages of rat colon tumor development. Cancer Res. 1987, 47, 5340-5346.

67. Bonizzi, G.; Karin, M. The two NF-kappaB activation pathways and their role in innate and adaptive immunity. Trends Immunol. 2004, 25, 280-288.

68. Crabtree, J.E.; Court, M.; Aboshkiwa, M.A.; Jeremy, A.H.; Dixon, M.F.; Robinson, P.A. Gastric mucosal cytokine and epithelial cell responses to Helicobacter pylori infection in Mongolian gerbils. J. Pathol. 2004, 202, 197-207.

69. Yamaoka, Y.; Yamauchi, K.; Ota, H.; Sugiyama, A.; Ishizone, S.; Graham, D.Y.; Maruta, F.; Murakami, M.; Katsuyama, T. Natural history of gastric mucosal cytokine expression in Helicobacter pylori gastritis in Mongolian gerbils. Infect. Immun. 2005, 73, 2205-2212.

70. Kim, S.G.; Kim, J.S.; Kim, J.M.; Jung, H.C.; Song, I.S. Inhibition of proinflammatory cytokine expression by NF-kappaB (p65) antisense oligonucleotide in Helicobacter pylori-infected mice. Helicobacter 2005, 10, 559-566.

71. Yanai, A.; Maeda, S.; Shibata, W.; Hikiba, Y.; Sakamoto, K.; Nakagawa, H.; Ohmae, T.; Hirata, Y.; Ogura, K.; Muto, S.; et al. Activation of $\mathrm{I} \kappa \mathrm{B}$ kinase $\beta$ and NF- $\kappa \mathrm{B}$ is essential for Helicobacter pylori-induced chronic gastritis in Mongolian gerbils. Infect. Immun. 2008, 76, 781-787.

72. Ogura, K.; Maeda, S.; Nakao, M.; Watanabe, T.; Tada, M.; Kyutoku, T.; Yoshida, H.; Shiratori, Y.; Omata, M. Virulence factors of Helicobacter pylori responsible for gastric diseases in Mongolian gerbil. J. Exp. Med. 2000, 192, 1601-1610.

73. Wu, C.S.; Chen, M.F.; Lee, I.L.; Tung, S.Y. Predictive role of nuclear factor-kappaB activity in gastric cancer: A promising adjuvant approach with caffeic acid phenethyl ester. J. Clin. Gastroenterol. 2007, 41, 894-900.

74. Toyoda, T.; Tsukamoto, T.; Takasu, S.; Shi, L.; Hirano, N.; Ban, H.; Kumagai, T.; Tatematsu, M. Anti-inflammatory effects of caffeic acid phenethyl ester (CAPE), a nuclear factor-kappaB inhibitor, on Helicobacter pylori-induced gastritis in Mongolian gerbils. Int. J. Cancer 2009, 125, 1786-1795. 
75. Baigent, C.; Keech, A.; Kearney, P.M.; Blackwell, L.; Buck, G.; Pollicino, C.; Kirby, A.; Sourjina, T.; Peto, R.; Collins, R.; et al. Efficacy and safety of cholesterol-lowering treatment: Prospective meta-analysis of data from 90,056 participants in 14 randomised trials of statins. Lancet 2005, 366, 1267-1278.

76. Hebert, P.R.; Gaziano, J.M.; Chan, K.S.; Hennekens, C.H. Cholesterol lowering with statin drugs, risk of stroke, and total mortality. An overview of randomized trials. JAMA 1997, 278, $313-321$.

77. Demierre, M.F.; Higgins, P.D.; Gruber, S.B.; Hawk, E.; Lippman, S.M. Statins and cancer prevention. Nat. Rev. Cancer 2005, 5, 930-942.

78. Dulak, J.; Jozkowicz, A. Anti-angiogenic and anti-inflammatory effects of statins: Relevance to anti-cancer therapy. Curr. Cancer Drug Targets 2005, 5, 579-594.

79. Poynter, J.N.; Gruber, S.B.; Higgins, P.D.; Almog, R.; Bonner, J.D.; Rennert, H.S.; Low, M.; Greenson, J.K.; Rennert, G. Statins and the risk of colorectal cancer. N. Engl. J. Med. 2005, 352, 2184-2192.

80. Toyoda, T.; Tsukamoto, T.; Takasu, S.; Hirano, N.; Ban, H.; Shi, L.; Kumagai, T.; Tanaka, T.; Tatematsu, M. Pitavastatin fails to lower serum lipid levels or inhibit gastric carcinogenesis in Helicobacter pylori-infected rodent models. Cancer Prev. Res. 2009, 2, 751-758.

81. Greenblatt, M.S.; Bennett, W.P.; Hollstein, M.; Harris, C.C. Mutations in the p53 tumor suppressor gene: Clues to cancer etiology and molecular pathogenesis. Cancer Res. 1994, 54, $4855-4878$.

82. Hirayama, Y.; Wakazono, K.; Yamamoto, M.; Kitano, M.; Tatematsu, M.; Nagao, M.; Sugimura, T.; Ushijima, T. Rare mutations of p53, Ki-ras, and $\beta$-catenin genes and absence of K-sam and c-erbB-2 amplification in $N$-methyl- $N$ '-nitro- $N$-nitrosoguanidine-induced rat stomach cancers. Mol. Carcinog. 1999, 25, 42-47.

83. Furihata, C.; Tatematsu, M.; Saito, M.; Ishida, S.; Nakanishi, H.; Inada, K.; Tei, H.; Hattori, M.; Ito, T.; Sakaki, Y. Rare occurrence of ras and p53 gene mutations in mouse stomach tumors induced by $N$-methyl- $N$-nitrosourea. Jpn. J. Cancer Res. 1997, 88, 363-368.

84. Donehower, L.A.; Harvey, M.; Slagle, B.L.; McArthur, M.J.; Montgomery, C.J.; Butel, J.S.; Bradley, A. Mice deficient for p53 are developmentally normal but susceptible to spontaneous tumours. Nature 1992, 356, 215-221.

85. Donehower, L.A.; Harvey, M.; Vogel, H.; McArthur, M.J.; Montgomery, C.A., Jr.; Park, S.H.; Thompson, T.; Ford, R.J.; Bradley, A. Effects of genetic background on tumorigenesis in p53-deficient mice. Mol. Carcinog. 1995, 14, 16-22.

86. Harvey, M.; McArthur, M.J.; Montgomery, C.J.; Butel, J.S.; Bradley, A.; Donehower, L.A. Spontaneous and carcinogen-induced tumorigenesis in p53-deficient mice. Nat. Genet. 1993, 5 , 225-229.

87. Yamamoto, M.; Tsukamoto, T.; Sakai, H.; Shirai, N.; Ohgaki, H.; Furihata, C.; Donehower, L.A.; Yoshida, K.; Tatematsu, M. p53 knockout mice (-/-) are more susceptible than (+/-) or $(+/+)$ mice to $N$-methyl- $N$-nitrosourea stomach carcinogenesis. Carcinogenesis 2000, 21, 1891-1897. 
88. Yamamoto, M.; Furihata, C.; Fujimitsu, Y.; Imai, T.; Inada, K.; Nakanishi, H.; Tatematsu, M. Dose-dependent induction of both pepsinogen-altered pyloric glands and adenocarcinomas in the glandular stomach of $\mathrm{C} 3 \mathrm{H}$ mice treated with $N$ - methyl- $N$-nitrosourea. Jpn. J. Cancer Res. 1997, $88,238-244$.

89. Tatematsu, M.; Furihata, C.; Katsuyama, T.; Mera, Y.; Inoue, T.; Matsushima, T.; Ito, N. Immunohistochemical demonstration of pyloric gland-type cells with low-pepsinogen isozyme 1 in preneoplastic and neoplastic tissues of rat stomachs treated with $N$-methyl- $N$ '-nitro- $N$ nitrosoguanidine. J. Natl. Cancer Inst. 1987, 78, 771-777.

90. Tatematsu, M.; Furihata, C.; Mera, Y.; Shirai, T.; Matsushima, T.; Ito, N. Immunohistochemical demonstration of induction of pyloric glands with low pepsinogen 1 (Pg 1) content in rat stomach by $N$-methyl- $N$ '-nitro- $N$ - nitrosoguanidine. Jpn. J. Cancer Res. 1986, 77, 238-243.

91. Ohgaki, H.; Fukuda, M.; Tohma, Y.; Huang, H.; Stoica, G.; Tatematsu, M.; Donehower, L.A. Effect of intragastric application of $N$-methylnitrosourea in p53 knockout mice. Mol. Carcinog. 2000, 28, 97-101.

92. Oshima, H.; Oshima, M.; Inaba, K.; Taketo, M.M. Hyperplastic gastric tumors induced by activated macrophages in COX-2/mPGES-1 transgenic mice. EMBO J. 2004, 23, 1669-1678.

93. Oshima, M.; Oshima, H.; Matsunaga, A.; Taketo, M.M. Hyperplastic gastric tumors with spasmolytic polypeptide-expressing metaplasia caused by tumor necrosis factor-alpha-dependent inflammation in cyclooxygenase-2/microsomal prostaglandin E synthase-1 transgenic mice. Cancer Res. 2005, 65, 9147-9151.

94. Oshima, H.; Matsunaga, A.; Fujimura, T.; Tsukamoto, T.; Taketo, M.M.; Oshima, M. Carcinogenesis in mouse stomach by simultaneous activation of the Wnt signaling and prostaglandin E2 pathway. Gastroenterology 2006, 131, 1086-1095.

95. Oshima, H.; Itadani, H.; Kotani, H.; Taketo, M.M.; Oshima, M. Induction of prostaglandin E2 pathway promotes gastric hamartoma development with suppression of bone morphogenetic protein signaling. Cancer Res. 2009, 69, 2729-2733.

96. Ishimoto, T.; Oshima, H.; Oshima, M.; Kai, K.; Torii, R.; Masuko, T.; Baba, H.; Saya, H.; Nagano, O. CD44+ slow-cycling tumor cell expansion is triggered by cooperative actions of Wnt and prostaglandin E2 in gastric tumorigenesis. Cancer Sci. 2010, 101, 673-678.

97. Oshima, H.; Hioki, K.; Popivanova, B.K.; Oguma, K.; Van Rooijen, N.; Ishikawa, T.O.; Oshima, M. Prostaglandin $\mathrm{E}_{2}$ signaling and bacterial infection recruit tumor-promoting macrophages to mouse gastric tumors. Gastroenterology 2011, 140, 596-607.

98. Takasu, S.; Tsukamoto, T.; Cao, X.Y.; Toyoda, T.; Hirata, A.; Ban, H.; Yamamoto, M.; Sakai, H.; Yanai, T.; Masegi, T.; et al. Roles of cyclooxygenase-2 and microsomal prostaglandin $\mathrm{E}$ synthase-1 expression and beta-catenin activation in gastric carcinogenesis in $\mathrm{N}$-methyl- $\mathrm{N}$ nitrosourea-treated K19-C2mE transgenic mice. Cancer Sci. 2008, 99, 2356-2364.

99. Clements, W.M.; Wang, J.; Sarnaik, A.; Kim, O.J.; MacDonald, J.; Fenoglio-Preiser, C.; Groden, J.; Lowy, A.M. beta-Catenin mutation is a frequent cause of Wnt pathway activation in gastric cancer. Cancer Res. 2002, 62, 3503-3506.

100. Tsukamoto, T.; Yamamoto, M.; Ogasawara, N.; Ushijima, T.; Nomoto, T.; Fujita, H.; Matsushima, T.; Nozaki, K.; Cao, X.; Tatematsu, M. beta-Catenin mutations and nuclear accumulation during progression of rat stomach adenocarcinomas. Cancer Sci. 2003, 94, 1046-1051. 
101. Cao, X.; Tsukamoto, T.; Nozaki, K.; Mizoshita, T.; Ogasawara, N.; Tanaka, H.; Takenaka, Y.; Kaminishi, M.; Tatematsu, M. Beta-catenin gene alteration in glandular stomach adenocarcinomas in $N$-methyl- $N$-nitrosourea-treated and Helicobacter pylori-infected Mongolian gerbils. Cancer Sci. 2004, 95, 487-490.

102. Du, Y.C.; Oshima, H.; Oguma, K.; Kitamura, T.; Itadani, H.; Fujimura, T.; Piao, Y.S.; Yoshimoto, T.; Minamoto, T.; Kotani, H.; et al. Induction and down-regulation of Sox17 and its possible roles during the course of gastrointestinal tumorigenesis. Gastroenterology 2009, 137, 1346-1357.

103. El-Omar, E.M.; Carrington, M.; Chow, W.H.; McColl, K.E.; Bream, J.H.; Young, H.A.; Herrera, J.; Lissowska, J.; Yuan, C.C.; Rothman, N.; et al. Interleukin-1 polymorphisms associated with increased risk of gastric cancer. Nature 2000, 404, 398-402.

104. Peleteiro, B.; Lunet, N.; Carrilho, C.; Duraes, C.; Machado, J.C.; La Vecchia, C.; Barros, H. Association between cytokine gene polymorphisms and gastric precancerous lesions: Systematic review and meta-analysis. Cancer Epidem. Biomar. 2010, 19, 762-776.

105. Gorouhi, F.; Islami, F.; Bahrami, H.; Kamangar, F. Tumour-necrosis factor-A polymorphisms and gastric cancer risk: A meta-analysis. Br. J. Cancer 2008, 98, 1443-1451.

106. Oshima, H.; Ishikawa, T.; Yoshida, G.J.; Naoi, K.; Maeda, Y.; Naka, K.; Ju, X.; Yamada, Y.; Minamoto, T.; Mukaida, N.; et al. TNF- $\alpha$ /TNFR1 signaling promotes gastric tumorigenesis through induction of Noxo1 and Gna14 in tumor cells. Oncogene 2013, doi:10.1038/onc.2013.356.

107. Shigematsu, Y.; Niwa, T.; Rehnberg, E.; Toyoda, T.; Yoshida, S.; Mori, A.; Wakabayashi, M.; Iwakura, Y.; Ichinose, M.; Kim, Y.J.; et al. Interleukin-1 $\beta$ induced by Helicobacter pylori infection enhances mouse gastric carcinogenesis. Cancer Lett. 2013, 340, 141-147.

108. Banerjee, A.; Thamphiwatana, S.; Carmona, E.M.; Rickman, B.; Doran, K.S.; Obonyo, M. Deficiency of the myeloid differentiation primary response molecule MyD88 leads to an early and rapid development of Helicobacter-induced gastric malignancy. Infect. Immun. 2014, 82, $356-363$.

109. Tomita, H.; Takaishi, S.; Menheniott, T.R.; Yang, X.; Shibata, W.; Jin, G.; Betz, K.S.; Kawakami, K.; Minamoto, T.; Tomasetto, C.; et al. Inhibition of gastric carcinogenesis by the hormone gastrin is mediated by suppression of TFF1 epigenetic silencing. Gastroenterology 2011, 140, 879-891.

110. Zavros, Y.; Eaton, K.A.; Kang, W.; Rathinavelu, S.; Katukuri, V.; Kao, J.Y.; Samuelson, L.C.; Merchant, J.L. Chronic gastritis in the hypochlorhydric gastrin-deficient mouse progresses to adenocarcinoma. Oncogene 2005, 24, 2354-2366.

111. Wang, T.C.; Dangler, C.A.; Chen, D.; Goldenring, J.R.; Koh, T.; Raychowdhury, R.; Coffey, R.J.; Ito, S.; Varro, A.; Dockray, G.J.; et al. Synergistic interaction between hypergastrinemia and Helicobacter infection in a mouse model of gastric cancer. Gastroenterology 2000, 118, 36-47.

112. Fox, J.G.; Wang, T.C.; Rogers, A.B.; Poutahidis, T.; Ge, Z.; Taylor, N.; Dangler, C.A.; Israel, D.A.; Krishna, U.; Gaus, K.; et al. Host and microbial constituents influence Helicobacter pyloriinduced cancer in a murine model of hypergastrinemia. Gastroenterology 2003, 124, 1879-1890.

113. Hayakawa, Y.; Fox, J.G.; Gonda, T.; Worthley, D.L.; Muthupalani, S.; Wang, T.C. Mouse models of gastric cancer. Cancers 2013, 5, 92-130. 
114. Nakayama, J.; Yeh, J.C.; Misra, A.K.; Ito, S.; Katsuyama, T.; Fukuda, M. Expression cloning of a human $\alpha 1,4-N$-acetylglucosaminyltransferase that forms GlcNAc $\alpha 1-->4 G a l \beta-->$ R, a glycan specifically expressed in the gastric gland mucous cell-type mucin. Proc. Natl. Acad. Sci. USA 1999, 96, 8991-8996.

115. Hidaka, E.; Ota, H.; Hidaka, H.; Hayama, M.; Matsuzawa, K.; Akamatsu, T.; Nakayama, J.; Katsuyama, T. Helicobacter pylori and two ultrastructurally distinct layers of gastric mucous cell mucins in the surface mucous gel layer. Gut 2001, 49, 474-480.

116. Kawakubo, M.; Ito, Y.; Okimura, Y.; Kobayashi, M.; Sakura, K.; Kasama, S.; Fukuda, M.N.; Fukuda, M.; Katsuyama, T.; Nakayama, J. Natural antibiotic function of a human gastric mucin against Helicobacter pylori infection. Science 2004, 305, 1003-1006.

117. Karasawa, F.; Shiota, A.; Goso, Y.; Kobayashi, M.; Sato, Y.; Masumoto, J.; Fujiwara, M.; Yokosawa, S.; Muraki, T.; Miyagawa, S.; et al. Essential role of gastric gland mucin in preventing gastric cancer in mice. J. Clin. Invest. 2012, 122, 923-934.

118. Shiratsu, K.; Higuchi, K.; Nakayama, J. Loss of gastric gland mucin-specific $O$-glycan is associated with progression of differentiated-type adenocarcinoma of the stomach. Cancer Sci. 2014, 105, 126-133.

119. Hofman, V.J.; Moreilhon, C.; Brest, P.D.; Lassalle, S.; Le Brigand, K.; Sicard, D.; Raymond, J.; Lamarque, D.; Hebuterne, X.A.; Mari, B.; et al. Gene expression profiling in human gastric mucosa infected with Helicobacter pylori. Mod. Pathol. 2007, 20, 974-989.

120. Hippo, Y.; Taniguchi, H.; Tsutsumi, S.; Machida, N.; Chong, J.M.; Fukayama, M.; Kodama, T.; Aburatani, H. Global gene expression analysis of gastric cancer by oligonucleotide microarrays. Cancer Res. 2002, 62, 233-240.

121. Kobayashi, M.; Lee, H.; Schaffer, L.; Gilmartin, T.J.; Head, S.R.; Takaishi, S.; Wang, T.C.; Nakayama, J.; Fukuda, M. A distinctive set of genes is upregulated during the inflammationcarcinoma sequence in mouse stomach infected by Helicobacter felis. J. Histochem. Cytochem. 2007, 55, 263-274.

122. Takaishi, S.; Wang, T.C. Gene expression profiling in a mouse model of Helicobacter-induced gastric cancer. Cancer Sci. 2007, 98, 284-293.

123. Abe, M.; Yamashita, S.; Kuramoto, T.; Hirayama, Y.; Tsukamoto, T.; Ohta, T.; Tatematsu, M.; Ohki, M.; Takato, T.; Sugimura, T.; et al. Global expression analysis of $N$-methyl- $N$ '-nitro- $N$ nitrosoguanidine-induced rat stomach carcinomas using oligonucleotide microarrays. Carcinogenesis 2003, 24, 861-867.

124. Itadani, H.; Oshima, H.; Oshima, M.; Kotani, H. Mouse gastric tumor models with prostaglandin E2 pathway activation show similar gene expression profiles to intestinal-type human gastric cancer. BMC Genomics 2009, 10, 615.

125. Toyoda, T.; Tsukamoto, T.; Yamamoto, M.; Ban, H.; Saito, N.; Takasu, S.; Shi, L.; Saito, A.; Ito, S.; Yamamura, Y.; et al. Gene expression analysis of a Helicobacter pylori-infected and high-salt diet-treated mouse gastric tumor model: Identification of CD177 as a novel prognostic factor in patients with gastric cancer. BMC Gastroenterol. 2013, 13, 122. 
126. Maekita, T.; Nakazawa, K.; Mihara, M.; Nakajima, T.; Yanaoka, K.; Iguchi, M.; Arii, K.; Kaneda, A.; Tsukamoto, T.; Tatematsu, M.; et al. High levels of aberrant DNA methylation in Helicobacter pylori-infected gastric mucosae and its possible association with gastric cancer risk. Clin. Cancer Res. 2006, 12, 989-995.

127. Niwa, T.; Tsukamoto, T.; Toyoda, T.; Mori, A.; Tanaka, H.; Maekita, T.; Ichinose, M.; Tatematsu, M.; Ushijima, T. Inflammatory processes triggered by Helicobacter pylori infection cause aberrant DNA methylation in gastric epithelial cells. Cancer Res. 2010, 70, 1430-1440.

128. Niwa, T.; Toyoda, T.; Tsukamoto, T.; Mori, A.; Tatematsu, M.; Ushijima, T. Prevention of Helicobacter pylori-induced gastric cancers in gerbils by a DNA demethylating agent. Cancer Prev. Res. 2013, 6, 263-270.

129. Nanjo, S.; Asada, K.; Yamashita, S.; Nakajima, T.; Nakazawa, K.; Maekita, T.; Ichinose, M.; Sugiyama, T.; Ushijima, T. Identification of gastric cancer risk markers that are informative in individuals with past $H$. pylori infection. Gastric Cancer 2012, 15, 382-388.

130. Hayashi, Y.; Tsujii, M.; Wang, J.; Kondo, J.; Akasaka, T.; Jin, Y.; Li, W.; Nakamura, T.; Nishida, T.; Iijima, H.; et al. CagA mediates epigenetic regulation to attenuate let-7 expression in Helicobacter pylori-related carcinogenesis. Gut 2013, 62, 1536-1546.

(C) 2014 by the authors; licensee MDPI, Basel, Switzerland. This article is an open access article distributed under the terms and conditions of the Creative Commons Attribution license (http://creativecommons.org/licenses/by/3.0/). 